\title{
Revalidation of the Cognitive and Affective Mindfulness Scale - Revised (CAMS-R) With Its Newly Developed Chinese Version (Ch-CAMS-R)
}

\author{
Hau-Lung Chan, Lap-Yan Lo, Muriel Lin, and Nigel Thompson \\ Hong Kong Shue Yan University, Hong Kong
}

\begin{abstract}
$\bigcirc$ onsidering the strengths and weaknesses of currently available inventories measuring mindfulness for Chinese population, a need for a short and comprehensive inventory was identified. The present study therefore developed a written Chinese version of the Cognitive and Affective Mindfulness Scale - Revised (CAMS-R) that excels in its full range of conceptual coverage, employs widely accessible language, and is brief in length. The reliability and validity of the Ch-CAMS-R was examined and found to be compatible with the original version and with other inventories measuring mindfulness. Results of confirmatory factor analysis (CFA) and exploratory factor analysis (EFA) suggested allocation of two question items, without posing a threat to the four-factor (including attention, awareness, present-focus and acceptance) structure in both the CAMS-R and Ch-CAMS-R. In general, the present study supports that this four-factor structure is compatible with the conceptualidation of mindfulness in both United States and Hong Kong samples.
\end{abstract}

Keywords: mindfulness, attention, awareness, acceptance, present-focus

Mindfulness (Pali: sati; Sanskrit: smriti) is an elusive, yet central, idea in the 2,500-year-old tradition of Buddhist investigation and conceptualisation of mental process and functioning (Siegel, Germer, \& Olendzki, 2009). Literally translatable from the original Pali as 'memory' or 'to remember', mindfulness can generally be regarded as an observer's ability to become aware of, attend to, and remember phenomena in the internal and external milieux (Siegel et al., 2009; Travis \& Pearson, 2000). A critical element of mindfulness is its potentiation of non-judgmental yet fully engaged awareness of positive, negative, or neutral aspects of ongoing subjective experience. In the same vein, mindfulness is written as 念 in Chinese, Japanese Kanji and Korean Hanja. The ideograph 念 can be decomposed into an upper component, 今, denoting the 'present moment', and a lower component, 心, denoting an amalgam of 'mind', 'hear' and 'attention'. The ideographic decomposition echoes the emphasis on a hereand-now, processual, attentional focus in the concept of mindfulness. A deeply mindful awareness is not easily distracted from its chosen object(s), whether by thoughts of the past and future, or by competing stimuli in the present (Smallwood \& Schooler, 2006).

\section{Therapeutic Mindfulness}

The meaning of mindfulness has been further modified during its ongoing application in the realm of contemporary psychotherapy. Bishop and colleagues (2004) proposed a two-component model to describe an updated operationalisation of mindfulness in clinical and therapeutic settings. The first component is self-regulation of attention, which involves sustained attention, attention switching, and the inhibition of elaborative processing that may distract from one's direct experience. This component is consistent with the element of here-and-now, present-centred attentional focus. Individuals make an effort to notice the dynamic flows of thoughts, feelings, and sensations arising and passing in the field of awareness.

The second component has to do with the therapeutic relevance of the mindfulness concept. It is an attitudinal orientation of curiosity, openness, and acceptance. Sensations are not merely neutrally witnessed, but are met with an acceptance and a receptiveness that enhance one's tolerance for unpleasant feelings. This emphasis has been adopted by third-wave cognitive-behavioural therapies (CBT), with acceptance and commitment therapy (ACT) recognised as one notable example (Blackledge, 
2007). While traditional CBT focuses more on how individuals manage and take charge of their cognitive distortions and modify their behaviours, ACT encourages people to shift their energy onto enhancing awareness of all experiences (Hayes \& Wilson, 1994). Instead of trying to make changes and to emphasise the sense of normality, one works to accept the existence of all realities occurring in life. The acceptance (i.e., equanimous acknowledgment) of all positive and negative experiences reduces the capacity of those experiences to interfere with an individual's intention to take action toward more meaningful directions in life. The development of such psychological flexibility even enhances the opportunity for an individual to reach his/her optimal mental state.

In general, the central idea of mindfulness in the twocomponent model (Bishop et al., 2004) is consistent with the terminology adopted in major Buddhist traditions; for example, the Theravada and Mahayana traditions (Gallois, 2010; Lyu, 2012). Both emphasise the importance of awareness. A slight difference is that the two-component model differentiates awareness and acceptance as two separate components of mindfulness, whereas in Buddhist teaching, mindfulness concepts and practices are generally taught within the injunction of an overall attitude of 'non-judgment' (Pali/Sanskrit: alobha) to the continually arising flow of phenomena. This understanding eventually leads to a development of a sense of acceptance; for example, the individual is able to accept the state/condition he or she currently occupies.

\section{Studies on Mindfulness}

Empirical studies on mindfulness have proliferated over the past three to four decades. They have largely focused on its therapeutic effectiveness relating to emotional, cognitive, and biological enhancement (Davis \& Hayes, 2011). Meta-analyses have revealed that mindfulness relates to a reduction of negative affectivity and promotes a sense of wellbeing (Cramer, Lauche, Paul, \& Dobos, 2012; Hofmann, Sawyer, Witt, \& Oh, 2010; Kabat-Zinn, 2003; Klainin-Yobas, Cho, \& Creedy, 2012; McCarney, Schulz, \& Grey, 2012; Piet \& Hougaard, 2011; Piet, Zachariae, \& Würtzen, 2012; Vøllestad, Nielsen, \& Nielsen, 2012). The benefits of practising mindfulness are evidenced in both clinical and non-clinical populations (Baer, 2003; Grossman, Niemann, Schmidt, \& Walach, 2004). Mindfulness-based therapeutic treatments - for example, mindfulness-based stress reduction (MBSR) and mindfulness-based cognitive therapy $(\mathrm{MBCT})$ - have been found to be effective in reducing depression, anxiety, and substance abuse (Chiesa \& Serretti, 2013; Marchand, 2012).

The states of mindfulness have also been supported by physiological findings (e.g., Cahn \& Polich, 2006; Dunn, Hartigan, \& Mikulas, 1999). During meditation, an increased intensity of both alpha $(\alpha)$ and theta $(\theta)$ frequency bands in electroencephalography (EEG) record- ings was observed, which indicated the presence of an internalised attentional focus (Aftanas \& Golocheikine, 2001). On the other hand, studies on mindfulness with large sample pools usually rely on self-report based inventories. There are several popular inventories that are commonly adopted while measuring mindfulness in the literatures, including the Mindful Attention Awareness Scale (MAAS; Brown \& Ryan, 2003), the Five-Facet Mindfulness Questionnaire (FFMQ; Baer, Smith, Hopkins, Krietemeyer, \& Toney, 2006), and the Cognitive and Affective and Mindfulness Scale - Revised (CAMS-R; Feldman, Hayes, Kumar, Greeson, \& Laurenceau, 2007). Items in these inventories generally cover aspects of attentional focus, self-awareness and acceptance attitude, though there are variations in the emphasis on different aspects among the inventories. The MAAS aims to measure dispositional mindfulness and is able to tap into a unique quality of consciousness that relates to, and is predictive of, a variety of self-regulation and wellbeing constructs (Brown \& Ryan, 2003). It largely focuses on the attention and awareness aspects but is inadequate in its measurement of the attitude of acceptance (Ninfa, 2007). In contrast, the FFMQ subdivides mindfulness into five different facets, including observing, describing, acting with awareness, non-judging of inner experience, and non-reactivity to inner experience. Based on the two-component model architecture of Bishop et al. (2004), the awareness component is believed to correspond to the FFMQ subfacets of observation (i.e., the frequency of an individual to notice the changes of his/her sensation, emotion, and cognition) and description (i.e., an identification of the internal experiences). The FFMQ subfacet of acting with awareness is concerned with one's capacity for attentional focus to an ongoing task. Lastly, the attitude of acceptance is measured by FFMQ subfacets of non-judgment of inner experience and non-reactivity to inner experience, which refer to the frequency of allowing thoughts and feelings to come and go, without being absorbed or disturbed by them. In contrast, the CAMS-R is a 12-item, self-report scale derived from a four-factor model covering the major domains of mindfulness: attention regulation, present-focus, awareness, and non-judgment (Ninfa, 2007). The CAMS-R has obtained an acceptable internal consistency. It has been validated by both convergent and discriminant validity with concurrent measures of mindfulness, distress, wellbeing, emotion-regulation, and problem-solving approaches (Feldman et al., 2007). Although the Freiburg Mindfulness Scale (FMS) was shown to share a similar four-factor structure with the CAMS-R (Walach, Buchheld, Buttenmüller, Kleinknecht, \& Schmidt, 2006), further studies failed to replicate the results and different models were also proposed (Leigh, Bowen, \& Marlatt, 2005). Moreover, the FMS was established based on a classical Buddhism derived model of mindfulness, and the original instrument (i.e., the FMS with 30 items) was validated among samples of Buddhist meditators (Buchheld, Grossman, \& Walach, 2001). The meanings of some of the items may be 
misinterpreted by individuals not highly familiar with classical Buddhist concepts of mindfulness. This may hinder the generalisability of FMS in measuring mindfulness in general populations.

\section{Mindfulness Inventories in Chinese}

Compared to the development and the volume of research conducted in the United States and Europe, the study of mindfulness in Chinese societies is in an initial stage, even though the Chinese are one of the largest populations in the world to have traditionally practised mindfulness exercises (e.g., meditation, yoga, and qigong). A demand has arisen for Chinese language inventories measuring the parameters of mindfulness. At least two Chinese versions of self-report mindfulness inventories have been developed recently. They are the Chinese version of the Mindful Attention Awareness Scale (Ch-MAAS; Deng et al., 2011) and the Chinese version of the Five Facet Mindfulness Questionnaire (Ch-FFMQ; Deng, Liu, Rodriguez, \& Xia, 2012). Both of these were directly translated from the original English versions and underwent all standardised validation procedures. The Ch-MAAS obtained acceptable-to-satisfactory scores in Cronbach's alpha (0.85), the Guttman split-half test $(0.81)$, and testretest reliability (0.54). It was also found to be negatively correlated with negative affect and positively associated with positive affect, as well as with quality of life (Deng et al., 2011). Similarly, the Ch-FFMQ received acceptable scores in Cronbach's alpha, the Guttmann split-half test, and test-retest reliability. The five-facet model in the $\mathrm{CH}$ FFMQ was also supported by confirmatory factor analysis (Deng et al., 2012).

An obvious benefit of translating an original mindfulness inventory into Chinese is efficiency. Good quality questionnaires can be obtained within a relatively short period of time. The drawback, however, is that these Chinese versions also inherit the weaknesses of the original ones. The MAAS provides a reliable measure of individual's awareness and attentional focus but lacks the capability of measuring the attitude of acceptance. This inadequacy is, as expected, also found in the Ch-MAAS. With regard to the FFMQ, one of its potential weakness results from the data-driven method by which it was developed. The five-facet model employed in the FFMQ was originally based on five clusterings derived from exploratory factor analysis and later supported by confirmatory factor analysis. All items in the developmental phase came from different mindfulness inventories without any unifying theoretical orientation. Eventually, four of the five facets were found to be highly similar to those in the Kentucky Inventory of Mindfulness Skills (KIMS; Baer, Smith, \& Allen, 2004; Ninfa, 2007). Twenty-four out of 39 items of the FFMQ are the same as items from the KIMS. The additional fifth factor - that is, non-reactivity to inner experience- in the FFMQ that does not derive from KIMS showed a poor Cronbach's alpha score. In other words, the
FFMQ may not be a distinctive inventory with a specific theoretical perspective in measuring mindfulness.

\section{Aim of the Present Research}

Considering the limitations of the currently available Chinese version inventories measuring mindfulness, the present study tried to take up the challenge and develop a Chinese version of the Cognitive and Affective Mindfulness Scale-Revised (Ch-CAMS-R). The original CAMS-R is a 12 -item self-report inventory with a comprehensive coverage of mindfulness, including the aspects of attention regulation, present-focus, awareness, and non-judgment (Feldman et al., 2007; Ninfa, 2007). Compared to the MAAS, the CAMS-R is more capable of measuring the aspects of mindfulness in both classical Buddhist and contemporary clinical perspectives. Furthermore, the CAMS$\mathrm{R}$ demonstrates convergent and discriminant validity with the concurrent measures of mindfulness, distress, wellbeing, emotion-regulation, and problem-solving approaches (Feldman et al., 2007). A strong theoretical orientation and the supportive empirical findings empower the CAMS$\mathrm{R}$ to be a better-rounded and better balanced inventory with solid explanatory power in comparison to the FFMQ, which is a largely data-driven inventory. Proper translation and a full set of validation procedures were conducted for the Chinese version of the CAMS-R. In order to maintain quality, validation procedures are identical to those adopted in the original version. It was expected that the Chinese version of the CAMS-R would possess a similar level of reliability and validity as the original CAMS-R. An additional exploratory factor analysis (EFA) and confirmatory factor analysis (CFA) have been conducted to examine the factor structure of the newly constructed ChCAMS-R.

\section{Methodology}

\section{Participants}

There were 215 native Chinese-English bilingual undergraduates from Hong Kong Shue Yan University (50 males, 163 females) recruited in the present study. Their average age was $19.16,(S D=1.502)$. All of the participating undergraduates were from the social sciences stream. Their participation was completely voluntary without any reward for their participation.

\section{Preparation of the Ch-CAMS-R}

Back-translation (into English) was applied after translating all the items from the original CAMS-R into Chinese. The first phase of translation was performed by a bilingual postgraduate studying psychology who was familiar with the concept of mindfulness. The back-translation was then undertaken by a professional translator. The back-translated version was examined and compared by an independent bilingual assistant professor working in the department of Counseling and Psychology at Hong Kong Shue Yan University who was also familiar with 
the concept of mindfulness. The processes of translation, back-translation and final examination kept running until a full mutual agreement was met among the three involved parties. The researchers in this current study only bore a minimal role in the translation process so as to minimise any bias to the involved parties. The whole process was completed within 2 months.

\section{Measurement and Materials}

In order to examine the reliability and validity of the proposed Ch-CAMS-R, seven inventories, including the translated Ch-CAMS-R, were utilised. All criteria followed those adopted in the development of the original CAMS-R (Feldman et al., 2007).

The Ch-CAMS-R is a Chinese version of CAMS-R and its structure and items are identical to the original CAMS$\mathrm{R}$. Each item is measured by a 4-point Likert scale, where 1 represents rarely/not at all and 4 represents almost always (see Appendix B).

In order to validate the contents of the Ch-CAMS$\mathrm{R}$, three popular inventories measuring mindfulness that is, the original CAMS-R (see Appendix A), the ChMAAS and the Ch-FFMQ - were adopted and served this function. It was expected that scores in the newly developed Ch-CAMS-R should be positively correlated to the scores obtained in the original version of CAMS-R, Ch-MAAS, and Ch-FFMQ.

Convergent validity was examined by a reliable 15 -item self-report Trait Meta-Mood Scale (TMMS) that measures emotional intelligence (Lau et al., 2006; Salovey, Mayer, Goldman, Turvey, \& Palfai, 1995). A high level of mindfulness suggests good emotional regulation ability (Vujanovic, Bonn-Miller, Bernstein, McKee, \& Zvolensky, 2010). Mindfulness is also found to promote both emotional and physiological regulatory mechanisms that reduce chronic worry (Delgado et al., 2010). A positive relationship between the scores in the TMMS and the new Ch-CAMS-R was therefore expected.

Another type of convergent validity was examined by adopting two other inventories: the Depression Anxiety and Stress Scales Short-Form (DASS-21) and the Ruminative Responses Scale Modified (RRS-M). The DASS-21 is a 21-item self-report scale for assessing three negative emotional states of depression, anxiety, and tension-stress (Antony, Bieling, Cox, Enns, \& Swinson, 1998). The total score in the DASS-21 can also indicate negative affectivity (Henry \& Crawford, 2005). The RRS-M is a six-item scale measuring the level of rumination in response to depression (Nolen-Hoeksema, 1991, 2000). It assesses the likeliness of one withdrawing from the external environment and regressing into a self-isolated state of mind while experiencing unpleasant feelings. In line with the hereand-now engagement and the acceptance attitude typical of mindfulness, it was predicted that scores in the ChCAMS-R would be negatively correlated with the scores in both DASS-21 and RRS-M.
Table 1

Descriptive Findings of the Development of Ch-CAMS-R

\begin{tabular}{lrr}
\hline Measures & \multicolumn{1}{c}{ Mean } & \multicolumn{1}{c}{$S D$} \\
\hline CAMS-R & 32.02 & 3.81 \\
Ch-CAMS-R & 33.72 & 3.42 \\
Ch-MAAS & 56.19 & 9.43 \\
Ch-FFMQ & 119.07 & 16.41 \\
DASS-21 & 20.84 & 9.40 \\
RRS-M & 31.89 & 7.14 \\
TMMS & 49.05 & 5.36 \\
\hline
\end{tabular}

Table 2

Correlational Figures Among Ch-CAMS-R, CAMS-R, Ch-MAAS, Ch-FFMQ, TMMS, DASS-21 and RRS-M

\begin{tabular}{lcc}
\hline & CAMS-R & Ch-CAMS-R \\
\hline CAMS-R & $1^{* *}$ & $0.61^{* *}$ \\
Ch-CAMS-R & $0.61^{* *}$ & $1^{* *}$ \\
Ch-MAAS & $0.34^{* *}$ & $0.3^{* *}$ \\
Ch-FFMQ & $0.44^{* *}$ & $0.56^{* *}$ \\
DASS-21 & $-0.28^{* *}$ & $-0.28^{* *}$ \\
RRS-M & $-0.15^{*}$ & $-0.13 \#$ \\
TMMS & $0.28^{* *}$ & $-0.20^{* *}$ \\
\hline Note: ${ }^{*} p<.05 ;{ }^{* *} p<.01 ; \# p=.058$. &
\end{tabular}

\section{Procedure}

Participants were all recruited on campus and then invited to sit in a quiet room to fill in all seven inventories that were administered in random order. Each participant was required to finish the seven inventories on a single day. If a participant was unable to finish all seven inventories, that participant's data were not counted in the analysis. Participants could take a break at any time they needed. They were clearly notified that there was no consequence for withdrawing. They could even withdraw their own set of records after the data collection by sending their participant number code to the researchers. Besides acquiring the consent and providing a debriefing, researchers had minimal interaction with the participants so as to minimise any demand characteristics. Inventories were usually finished within 60 minutes. The data collection process was completed within 4 months.

\section{Results and Analysis}

Descriptive findings of different inventories are shown in Table 1. Cronbach's alpha was found to be acceptable to good in both the Ch-CAMS-R (0.67) and the CAMS$\mathrm{R}$ (0.66). Pearson correlations between the Ch-CAMS-R and other measures were computed to test the Ch-CAMSR's content and convergent validities. CFA was then performed to compare the factor structure of the Ch-CAMS-R with that of the original CAMS-R.

\section{Correlations Between the Ch-CAMS-R and Other Measures}

Pearson correlation coefficients of the Ch-CAMS-R with other measures are presented in Table 2. The 


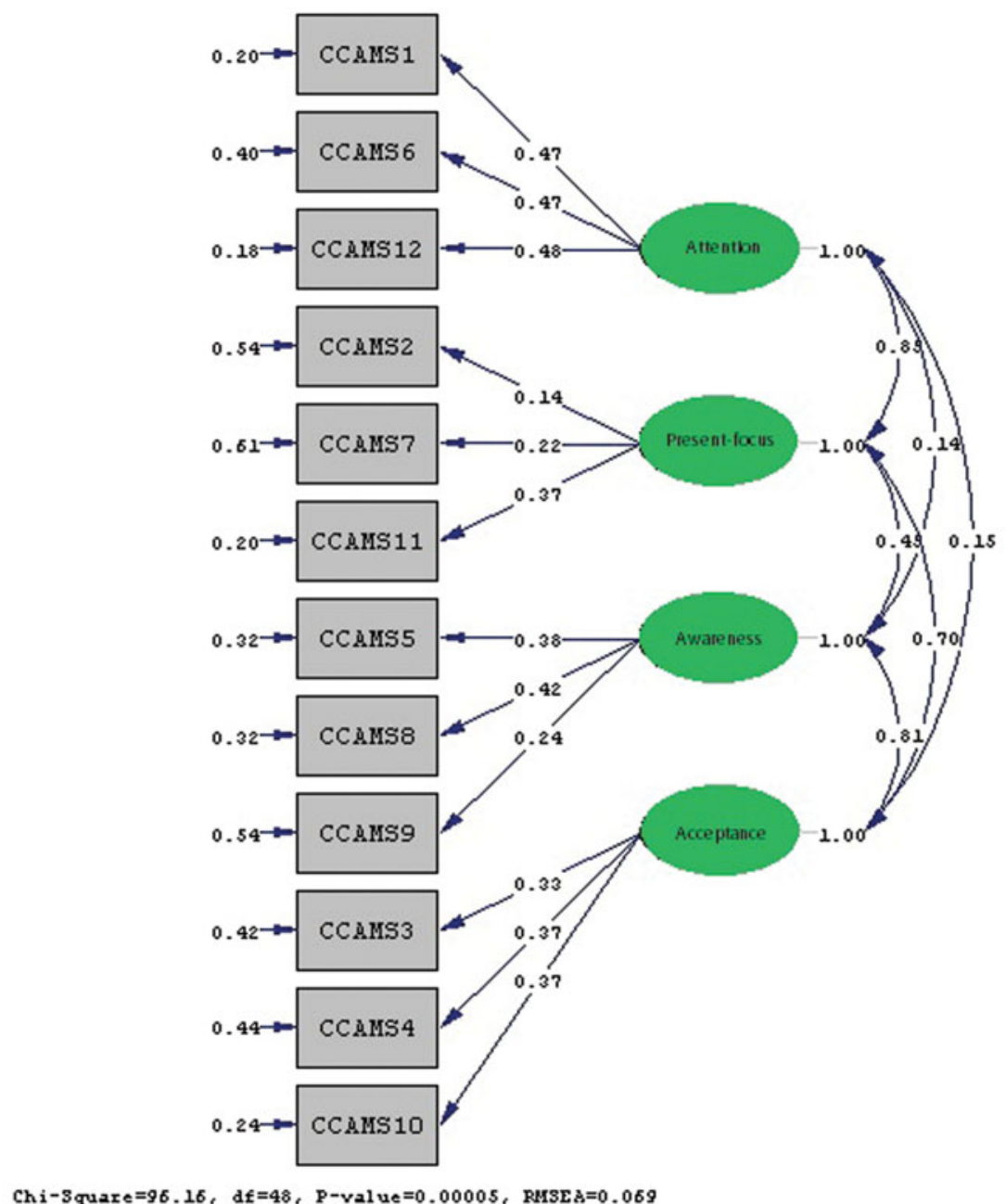

Chi-3 quare $=96.16, d f=48, p-v a l u e=0.00005$, RMSE $\mathrm{A}=0.069$

\section{Figure 1}

(Colour online) Path-diagram of the original model.

Note: Chi-square $=101.7, d f=48, p$ value $=.00005$, RMSEA $=0.069$.

Ch-CAMS-R was found to significantly positively correlate with the CAMS-R, Ch-MAAS, and Ch-FFMQ. With regard to convergent validity, the Ch-CAMS-R (and CAMS-R) was negatively correlated with the DASS-21 and RRS-M and positively associated with the TMMS. In sum, the convergent validity in the Ch-CAMS-R is compatible with the original version of the CAMS-R reported by Feldman and his colleagues (2007).

\section{Confirmatory Factor Analysis}

A CFA was conducted to examine the factor structure of the Ch-CAMS-R. A model with items with the same fourfactor structure proposed by the CAMS-R (i.e., the original model) was computed (see Figure 1). The chi square score was $101.7(p<.01)$. The RMSEA was 0.069 and SRMR was 0.064 . The score of the Comparative Fit Index (CFI), however, showed only a marginal fit of the original model (i.e., 0.89). In other words, the data collected in the present study did not completely fit the factor structure proposed in the original CAMS-R. It is possible that the conceptualisation of mindfulness can vary across cultures (Christopher et al., 2009). In order to explore the possible factor structure that might accommodate the present data set, an EFA was therefore conducted.

\section{Exploratory Factor Analysis}

An EFA was conducted to explore the factor structure of the Ch-CAMS-R and determine any redundancies among the items. The reason for not performing an EFA before a CFA in this study was that the Ch-CAMS-R was supposed to be in line with the clustering of the original CAMS-R; however, this was not supported by the present results. Hence, an EFA was conducted with the same sample set to explain the inconsistency by exploring the nature of the factors of the Ch-CAMS-R. Future studies with larger sample sizes may further examine the Ch-CAMS-R.

The data structure obtained in this study was assessed with the Kaiser-Meyer-Olkin measure, which yielded the value 0.69 , indicating that the data were appropriate for conducting an EFA. A principal component method was 


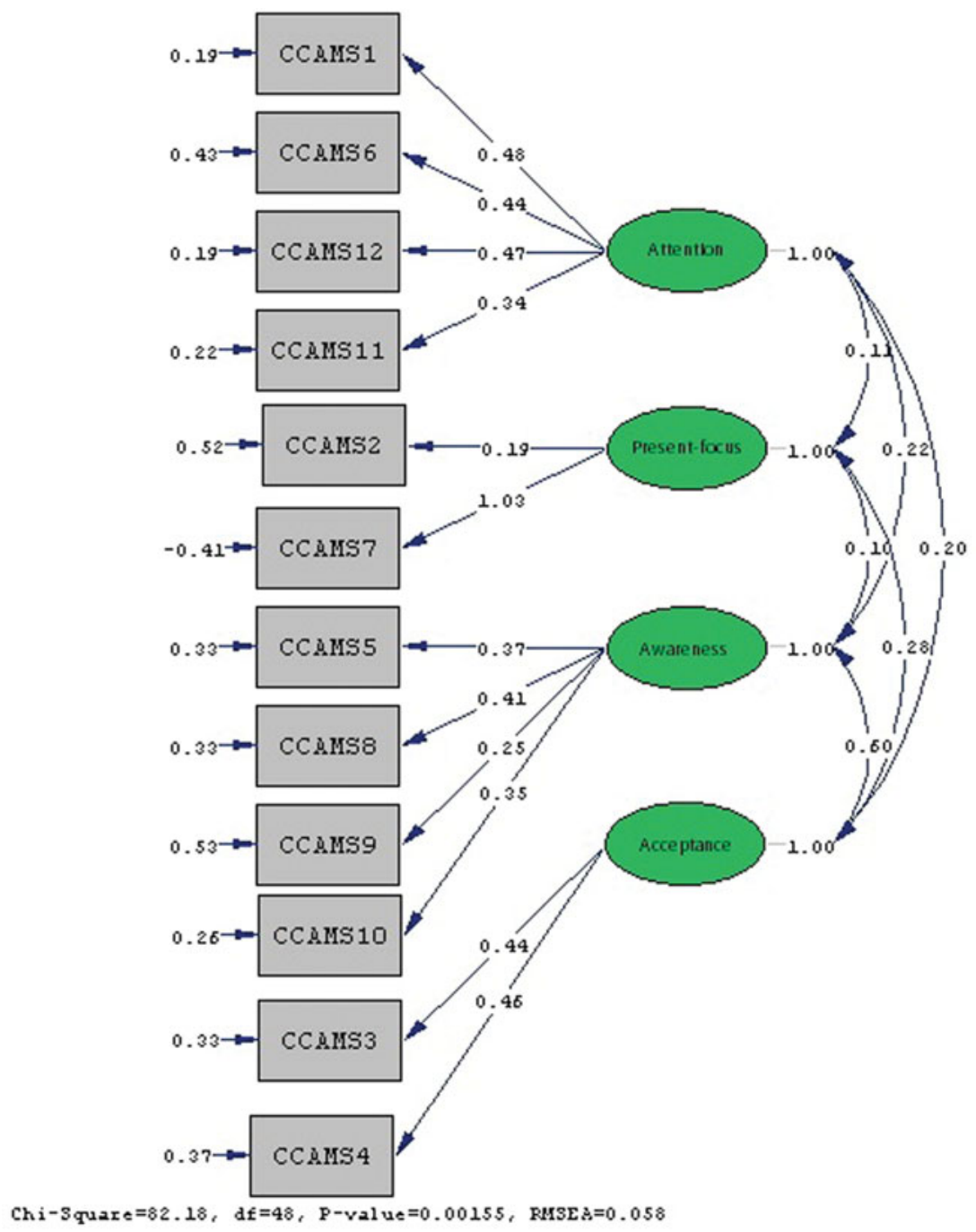

\section{Figure 2}

(Colour online) Path-diagram of the amended model.

Note: Chi-square $=83.61, d f=48, p$ value $=.00155, \operatorname{RMSEA}=0.058$.

used to extract factors and four factors were retained, with the combined factors accounting for approximately 59\% of the combined variance. Based on the factor loadings, factor 1 is interpreted as representing attention regulation, factor 2 is interpreted as representing awareness, factor 3 represents acceptance, and factor 4 denotes present-focus. This four-factor structure in the Ch-CAMS-R is similar to the factor structure of the original CAMS-R.

In looking at the specific items, it was found that one item (item 11), which was originally intended to measure present-focus, fell instead into the factor assessing attention regulation. Another item (item 10), which assessed acceptance in the original CAMS- $\mathrm{R}$, eventually loaded onto the factor measuring awareness in the Ch-CAMS-R. In other words, findings in an EFA suggested mild changes in the allocations of two items (items 10 and 11), but the four-factor structure remained the same.

An additional CFA was conducted based on the factor structure suggested by the EFA, that is, to an amended model (see Figure 2). The chi-square score was 83.61 ( $p<$ .01 ) and the RMSEA of this amended model was 0.058 . The comparative fit index (CFI) of the amended model showed a good fit (0.93) and the SRMR score was favourable (score $=0.063)$. Consistent with the results in the EFA, the amended model, with the reallocation of two items within the four-factor structure, is relatively preferable to the original one.

\section{Discussion}

Considering the strengths and weaknesses of the currently available Chinese version of inventories measuring mindfulness, the present study tried to construct a Chinese version of the CAMS-R, an inventory possessing comprehensive coverage of both theoretical and therapeutic aspects of mindfulness. In general, the Ch-CAMS-R has been found to obtain a similar level of reliability, validity, and factor structure as the original CAMS-R (Feldman 


\section{Table 3}

Item Arrangement in the Four-Factor Structure of CAMS-R

\begin{tabular}{|c|c|}
\hline Factors & Items in CAMS-R \\
\hline Attention & $\begin{array}{l}\text { 1. It is easy for me to concentrate on what I am } \\
\text { doing. } \\
6 \text {. I am easily distracted. } \\
\text { 12. I am able to pay close attention to one thing for a } \\
\text { long period of time. }\end{array}$ \\
\hline Present-focus & $\begin{array}{l}\text { 2. I am preoccupied by the future. } \\
\text { 7. I am preoccupied by the past. } \\
\text { 11. I am able to focus on the present moment.* }\end{array}$ \\
\hline Awareness & $\begin{array}{l}\text { 5. I can usually describe how I feel at the moment in } \\
\text { considerable detail. } \\
\text { 8. It's easy for me to keep track of my thoughts and } \\
\text { feelings. } \\
\text { 9. I try to notice my thoughts without judging them. }\end{array}$ \\
\hline Acceptance & $\begin{array}{l}\text { 3. I can tolerate emotional pain. } \\
\text { 4. I can accept things I cannot change. } \\
\text { 10. I am able to accept the thoughts and feelings I } \\
\text { have.\# }\end{array}$ \\
\hline
\end{tabular}

Note: *This item was suggested by the EFA to belong to the Attention factor. \#This item was suggested by the EFA to belong to the Awareness factor.

et al., 2007). The significant positive correlations among the Ch-CAMS-R, CAMS-R, Ch-FFMQ and Ch-MAAS indicate a good content validity. Good convergent validity is supported by its negative relationship to the DASS-21 and RRS-M, and a positive relationship to the TMMS. Factor structure of the Ch-CAMS-R was compared with the original CAMS-R and confirmed by the results in both EFA and CFA.

\section{Unexpected Items in Ch-CAMS-R}

The four-factor structure in the present Ch-CAMS-R fits into the theoretical basis of the original CAMS-R (Feldman et al., 2007). The four latent constructs in the ChCAMS- $\mathrm{R}$ were identified as attention regulation, presentfocus, awareness, and acceptance, which are consistent with both classical and clinical perspectives on mindfulness (Bishop et al., 2004; Siegel et al., 2009). Items assessing corresponding constructs are largely comparable between the Ch-CAMS-R and CAMS-R, with the exception of two items (see Table 3). One of the items (item 11: ‘我能豿集 中於當下的時刻' or 'I am able to focus on the present moment') was intended to measure present-focus but fell instead into the construct assessing attention regulation in the current study. It is suggested that the word '集 中' in item 11 primed the participants to associate the item with the meaning of attention focus. This bisyllabic term is commonly used with the meaning of attention in Chinese writing and conversation. This biasing effect might have therefore led the participants to bypass the keyword “當下的時刻” which means 'the present moment' instead of associating item 11 with the attention aspect.

Item 10 (“我能夠接納自己的思想和感受” or 'I am able to accept the thoughts and feelings I have'), which was expected to measure acceptance, fell into the construct as- sessing awareness in the current study. Items measuring acceptance in both the CAMS-R and Ch-CAMS-R usually describe how much an individual can tolerate events or experiences with negative valence; for example, 'I can tolerate emotional pain' (item 3 ) and 'I can accept things I cannot change' (item 4). Such negativity is less obvious, if apparent at all, in item 10. On the other hand, items assessing awareness (items 5, 8 and 9) emphasise the feeling and thinking that are similar to the wording in item 10. Participants in this current study again might have overlooked the keyword ‘接納' (i.e., acceptance) but focused more on the words '思想' and '感受' (i.e., thoughts and feelings) when filling in item 10 in the Ch-CAMS-R.

The performance of the participants in the present study generally corroborates the four-factor structure of mindfulness, including attention, awareness, presentfocus, and acceptance. Reliability, validity, and the conceptual structure in the Ch-CAMS-R were found to be highly similar to the original CAMS-R. In order to fulfill a more stringent criterion, future studies can try to rephrase the wordings in item 10 and item 11 and examine whether these two items can fall back to the original structure as proposed by the CAMS-R.

\section{Cultural Relevance}

Although the factor structure is mostly retained, two items were suggested to be reallocated in the Ch-CAMS-R, as suggested by the results in both the EFA and CFA. Other than the linguistic usage preference, past studies also suggest that the conceptualisation of mindfulness itself can be culturally varied. It was found, for example, that the model of mindfulness implicit in the KIMS was not equally applicable to the conceptualisations of mindfulness held by Thai college students and by United States college students (Christopher, Charoensuk, Gilbert, Neary, \& Pearce, 2009). Results from the EFA and CFA in their studies also indicated that there could be a different factor structure with a number of cross-loaded and negatively loaded items, which seemed to be dramatically different from the models proposed in the KIMS and MAAS. Supported by the findings in the present research, the Ch-CAMS-R can be perceived as largely compatible with its original version. The minor reallocation of the two items in the inventory does not pose a critical threat to the essence of the fourfactor structure as originally proposed in the CAMS-R. In other words, the conceptualisation of mindfulness as denoted by the CAMS-R and Ch-CAMS- $\mathrm{R}$ is equally viable in both U.S. and Hong Kong samples.

\section{Implications}

In reviewing previous mindfulness research, mindfulness has become increasingly prevalent in psychology over the past few decades. Mindfulness practices and techniques have already been incorporated into systematic clinical 
interventions. In order to meet the demand in the therapeutic domain, the conceptualisation of mindfulness has been transformed from a classical perspective to one that is therapeutically focused, by adding the aspect of acceptance. There is certainly a need for a comprehensive inventory appropriate to Chinese populations that covers the critical aspects of the concept of mindfulness. The Ch-MAAS focuses solely on the classical aspects whereas the long Ch-FFMQ is almost a replica of the KIMS. The introduction of the Ch-CAMS-R (originating from the CAMS-R) therefore provides an alternative platform for assessing mindfulness. The Ch-CAMS-R is good in terms of both comprehensive coverage of mindfulness and the brevity of the scale (i.e., only 12 items). The development of the Ch-CAMS-R can assist in the growing interest in mindfulness by Chinese researchers. Yoga, meditation, qigong, and Tai Chi have long been popularly practised in Chinese society, and mindfulness-based interventions have also gained favour among professional psychologists. The Ch-CAMS-R can also assist non-Chinese researchers to conduct studies on mindfulness with participants who only know Chinese. It is hoped that the Ch-CAMS-R will serve as an initial step and an exploration of clinically relevant mindfulness issues that may be able to further facilitate the trend of research, understanding, and application of mindfulness.

\section{Appendix A Cognitive and Affective Mindfulness Scale-Revised (CAMS-R)}

People have a variety of ways of relating to their thoughts and feelings. For each of the items below, rate how much each of these ways applies to you.

\begin{tabular}{|c|c|c|c|c|}
\hline & $\begin{array}{l}\text { Rarely/Not } \\
\text { at all }\end{array}$ & $\begin{array}{l}\text { Some- } \\
\text { times }\end{array}$ & Often & $\begin{array}{l}\text { Almost } \\
\text { always }\end{array}$ \\
\hline $\begin{array}{l}\text { 1. It is easy for me to } \\
\text { concentrate on what I am } \\
\text { doing. }\end{array}$ & $\circ$ & $\circ$ & o & $\circ$ \\
\hline $\begin{array}{l}\text { 2. I am preoccupied by the } \\
\text { future. }\end{array}$ & ○ & ○ & 0 & ○ \\
\hline 3. I can tolerate emotional pain. & ○ & ○ & ○ & ○ \\
\hline $\begin{array}{l}\text { 4. I can accept things I cannot } \\
\text { change. }\end{array}$ & ○ & ○ & 0 & ○ \\
\hline $\begin{array}{l}\text { 5. I can usually describe how I } \\
\text { feel at the moment in } \\
\text { considerable detail. }\end{array}$ & ○ & ○ & 0 & ○ \\
\hline 6. I am easily distracted. & ○ & ○ & ○ & ○ \\
\hline 7. I am preoccupied by the past. & $\circ$ & $\circ$ & ○ & ○ \\
\hline $\begin{array}{l}\text { 8. It's easy for me to keep track } \\
\text { of my thoughts and feelings. }\end{array}$ & $\circ$ & $\circ$ & $\circ$ & $\circ$ \\
\hline $\begin{array}{l}\text { 9. I try to notice my thoughts } \\
\text { without judging them. }\end{array}$ & ○ & ○ & 0 & ○ \\
\hline $\begin{array}{l}\text { 10. I am able to accept the } \\
\text { thoughts and feelings I have. }\end{array}$ & ○ & ○ & o & ○ \\
\hline $\begin{array}{l}\text { 11. I am able to focus on the } \\
\text { present moment. }\end{array}$ & ○ & $\circ$ & $\circ$ & $\circ$ \\
\hline $\begin{array}{l}\text { 12. I am able to pay close } \\
\text { attention to one thing for a } \\
\text { long period of time. }\end{array}$ & $\circ$ & $\circ$ & $\circ$ & $\circ$ \\
\hline
\end{tabular}

\section{Appendix B \\ Chinese version of Cognitive and Affective Mindfulness Scale - Revised (Ch-CAMS-R)}

人總有不同方式去整合他們的思想和感受.請衡量以 下句子有多少適合你

\begin{tabular}{|c|c|c|c|c|}
\hline & $\begin{array}{l}\text { 絕少/ } \\
\text { 從不 }\end{array}$ & 間中 & 經常 & $\begin{array}{l}\text { 接近 } \\
\text { 總是 }\end{array}$ \\
\hline $\begin{array}{l}\text { 1. 對我來說，我很容易集中在我正 在做 } \\
\text { 的事上 }\end{array}$ & $\circ$ & $\circ$ & $\circ$ & $\circ$ \\
\hline 2. 對未來的擔憂佔去了我的注意力 & $\circ$ & $\circ$ & $\circ$ & $\circ$ \\
\hline 3. 我能夠忍受情感上的痛楚 & $\circ$ & $\circ$ & $\circ$ & $\circ$ \\
\hline $\begin{array}{l}\text { 4. 我能夠接受有些事是我不能夠轉 變 } \\
\text { 的 }\end{array}$ & $\circ$ & $\circ$ & $\circ$ & $\circ$ \\
\hline $\begin{array}{l}\text { 5. 我通常能夠非常詳細地形容我當下 } \\
\text { 的感受 }\end{array}$ & $\circ$ & $\circ$ & $\circ$ & $\circ$ \\
\hline 6. 我是容易分心的 & $\circ$ & $\circ$ & $\circ$ & $\circ$ \\
\hline 7. 對過去的擔憂佔去了我的注意力 & $\circ$ & $\circ$ & $\circ$ & $\circ$ \\
\hline $\begin{array}{l}\text { 8. 對我來說, 我容易持續地觀察和分辨 } \\
\text { 自己的思想和感覺的變化 }\end{array}$ & $\circ$ & $\circ$ & $\circ$ & $\circ$ \\
\hline $\begin{array}{l}\text { 9. 我嘗試去留意自己的想法，而又不判 } \\
\text { 斷它們是好的或是壞的 }\end{array}$ & $\circ$ & $\circ$ & $\circ$ & $\circ$ \\
\hline 10. 我能夠接納自己的思想和感受 & $\circ$ & $\circ$ & $\circ$ & $\circ$ \\
\hline 11. 我能夠集中於當下的時刻 & $\circ$ & $\circ$ & $\circ$ & $\circ$ \\
\hline 12. 我能夠在一件事上集中一段長時 間 & $\circ$ & $\circ$ & $\circ$ & $\circ$ \\
\hline
\end{tabular}

\section{References}

Aftanas, L.I., \& Golocheikine, S.A. (2001). Human anterior and frontal midline theta and lower alpha reflect emotionally positive state and internalized attention: high-resolution EEG investigation of meditation. Neuroscience Letters, 310, 57-60. doi:10.1007/s10484-008-9050-5

Antony, M.M., Bieling, P.J., Cox, B.J., Enns, M.W., \& Swinson, R.P. (1998). Psychometric properties of the 42-item and 21item versions of the Depression Anxiety Stress Scales in clinical groups and a community sample. Psychological Assessment, 10, 176-181. doi:10.1037/1040-3590.10.2.176

Baer, R.A. (2003). Mindfulness training as a clinical intervention: A conceptual and empirical review. Clinical Psychology: Science \& Practice, 10, 125-143. doi:10.1093/clipsy/bpg015

Baer, R.A., Smith, G.T., \& Allen, K.B. (2004). Assessment of Mindfulness by Self-Report: The Kentucky Inventory of Mindfulness Skills. Assessment, 11, 191-206. doi:10.1177/1073191104268029

Baer, R.A., Smith, G.T., Hopkins, J., Krietemeyer, J., \& Toney, L. (2006). Using self-report assessment methods to explore facets of mindfulness. Assessment, 13, 27-45. doi: $10.1177 / 1073191105283504$

Bishop, S., Lau, M., Shapiro, S., Carlson, L., Anderson, N., Carmody, J., ... Devins, G. (2004). Mindfulness: A proposed operational definition. Clinical Psychology: Science and Practice, 11, 230-241. doi:10.1093/clipsy.bph077

Blackledge, J.T. (2007). Disrupting verbal processes: Cognitive defusion in acceptance and commitment therapy and other mindfulness-based psychotherapies. The Psychological Record, 57, 555-576. doi:10.1016/j.concog.2014.06.005 
Brown, K.W., \& Ryan, R.M. (2003). The benefits of being present: Mindfulness and its role in psychological well-being. Journal of Personality and Social Psychology, 84, 822-848. doi:10.1037/0022-3514.84.4.822. 822

Buchheld, N., Grossman, P., \& Walach, H. (2001). Measuring mindfulness in insight meditation (Vipassana) and meditation-based psychotherapy: The development of the Freiburg Mindfulness Inventory (FMI). Journal for Meditation and Meditation Research, 1, 11-34.

Cahn, B.R., \& Polich, J. (2006). Meditation states and traits: EEG, ERP, and neuroimagingstudies. Psychological Bulletin, 132, 180-211. doi:10.1037/0033-2909.132.2.180

Chiesa, A., \& Serretti, A. (2013). Are mindfulness-based interventions effective for substance use disorders? A systematic review of the evidence. Substance Use \& Misuse, 49, 492-512. doi:10.3109/10826084.2013.770027

Christopher, M.S., Charoensuk, S., Gilbert, B.D., Neary, T.J., \& Pearce, K.L. (2009). Mindfulness in Thailand and the United States: A case of apples versus oranges? Journal of Clinical Psychology, 65, 590-612. doi:10.1002/jclp.20580

Cramer, H., Lauche, R., Paul, A., \& Dobos, G. (2012) Mindfulness-based stress reduction for breast cancer: A systematic review and meta-analysis. Current Oncology, 19, 343352. doi:10.3747/co.19.1016

Davis, D.M., \& Hayes, J.A. (2011). What are the benefits of mindfulness? A practice review of psychotherapy-related research. Psychotherapy, 48, 198-208. doi:10.1037/a0022062

Delgado, L.C., Guerra, P., Perakakis, P., Vera, M.N., Reyes del Paso, G., \& Vila, J. (2010). Treating chronic worry: Psychological and physiological effects of a training programme based on mindfulness. Behaviour Research \& Therapy, 48, 873-882. doi:10.1016/j.brat.2010.05.012

Deng, Y.Q., Li, S., Tang, Y.Y., Zhu, L.H., Ryan, R., \& Brown, K. (2011). Psychometric Properties of the Chinese Translation of the Mindful Attention Awareness Scale (MAAS). Mindfulness, 3, 10-14. doi:10.1007/s12671-011-0074-1

Deng, Y.Q., Liu, X.H., Rodriguez, M.A., \& Xia, C.Y. (2012). The Five Facet Mindfulness Questionnaire: Psychometric Properties of the Chinese Version. Mindfulness, 2, 123-128. doi:10.1007/s12671-011-0050-9

Dunn, B.R., Hartigan, J.A., \& Mikulas, W.L. (1999). Concentration and mindfulness meditations: unique forms of consciousness? Applied Psychophysiology Biofeedback, 24, 14765. doi:10.1016/j.jphysparis.2015.03.001

Feldman, G., Hayes, A., Kumar, S., Greeson, J., \& Laurenceau, J.P. (2007). Mindfulness and Emotion Regulation: The Development and Initial Validation of the Cognitive and Affective Mindfulness Scale-Revised (CAMS-R). Journal of Psychopathological Behavioral Assessment, 29, 177-190. doi:10.1007/s10862-006-9035-8

Gallois, W. (2010). Zen history. Rethinking History: The Journal of Theory and Practice, 14, 421-440. doi:10.1080/13642529.2010.482799

Grossman, P., Niemann, L., Schmidt, S., \& Walach, H. (2004). Mindfulness-based stress reduction and health-benefits: A meta-analysis. Journal of Psychosomatic Research, 57, 35-43. doi:10.1111/j.2042-7166.2003.tb04008.x
Hayes, S.C., \& Wilson, K.G. (1994). Acceptance and commitment therapy: Altering the verbal support for experiential avoidance. The Behavior Analyst, 17, 289-303. doi:10.1016/S1077-7229(98)80006-0

Henry, J.D., \& Crawford, J.R. (2005). The short-form version of the depression anxiety stress scales (DASS-21): Construct validity and normative data in a large non-clinical sample. British Journal of Clinical Psychology, 44, 227-239. doi:10.1348/014466505X29657

Hofmann, S.G., Sawyer, A.T., Witt, A.A., \& Oh, D. (2010). The effect of mindfulness-based therapy on anxiety and depression: A meta-analytic review. Journal of Consulting \& Clinical Psychology, 78, 169-183. doi: 10.1037/a0018555

Kabat-Zinn, J. (2003). Mindfulness-based interventions in context: Past, present, and future. Clinical Psychology: Science \& Practice, 10, 144-156. doi: 10.1093/clipsy/bpg016

Klainin-Yobas, P., Cho, M.A.A., \& Creedy, D. (2012). Efficacy of mindfulness-based interventions on depressive symptoms among people with mental disorders: A metaanalysis. International Journal of Nursing Studies, 49, 109121. doi:10.1016/j.ijnurstu.2011.08.014

Lau, M.A., Bishop, S.R., Segal, Z.V., Buis, T., Anderson, N.D., Carlson, L., ... Devine, G. (2006). The Toronto mindfulness scale: development and validation. Journal of Clinical Psychology, 62, 1445-1467. doi:10.1002/jclp.20326

Leigh, J., Bowen, S., \& Marlatt, G.A. (2005). Spirituality, mindfulness and substance abuse. Addict Behavior, 30, 1335-1341.

Lyu, S.H. (2012). Development and mission of Theravada and Mahayana Buddhism in an era of globalization. Religion East \& West, 11, 45-51.

Marchand, W.R. (2012). Mindfulness-based stress reduction, mindfulness-based cognitive therapy, and zen meditation for depression, anxiety, pain, and psychological distress. Journal of Psychiatric Practice, 18, 233-252. doi:10.1097/01.pra.0000416014.53215.86

McCarney, R.W., Schulz, J., \& Grey, A.R. (2012). Effectiveness of mindfulness-based therapies in reducing symptoms of depression: A meta-analysis. European Journal of Psychotherapy \& Counselling, 14, 279-299. doi:10.1080/13642537.2012.713186

Ninfa, J. (2007). Self-report measures of mindfulness: A review of the literature (Master's thesis, Pacific University). Retrieved from http://commons.pacificu.edu/spp/6

Nolen-Hoeksema, S. (1991). Responses to depression and their effects on the duration of depressive episodes. Journal of Abnormal Psychology, 100, 569-582. doi:10.1037//0021-843X.100.4.569

Nolen-Hoeksema, S. (2000). The role of rumination in depressive disorders and mixed anxiety/depressive symptoms. Journal of Abnormal Psychology, 109, 504-511. doi:101037/10021-843X.109.3.504

Piet, J., \& Hougaard, E. (2011). The effect of mindfulnessbased cognitive therapy for prevention of relapse in recurrent major depressive disorder: A systematic review and meta-analysis. Clinical Psychology Review, 31, 1032-1040. doi:10.1016/j.cpr.2011.05.002 
Piet, J., Zachariae, R., \& Würtzen, H. (2012). The effect of mindfulness-based therapy on symptoms of anxiety and depression in adult cancer patients and survivors: A systematic review and meta-analysis. Journal of Consulting \& Clinical Psychology, 80, 1007-1020. doi:10.1037/a0028329

Salovey, P., Mayer, J.D., Goldman, S.L., Turvey, C., \& Palfai, T.P. (1995). Emotional attention, clarity, and repair: Exploring emotional intelligence using the Trait Meta-Mood Scale. In J.W. Pennebaker (Ed.), Emotion, disclosure, and health (pp. 125-154). Washington, DC: American Psychological Association.

Smallwood, J., \& Schooler, J.W. (2006). The restless mind. Psychological Bulletin, 132, 946-958. doi:10.1037/0033-2909.132.6.946

Siegel, R.D., Germer, C.K., \& Olendzki, A. (2009). Mindfulness: What is it? Where did it come from? In F. Didonna (Ed.), Clinical handbook of mindfulness (pp. 17-35). New York: Springer.
Travis, F., \& Pearson, C. (2000). Pure consciousness: Distinct phenomenological and physiological correlates of 'consciousness itself'. The International Journal of Neuroscience, 100, 77-89. doi:10.3109/00207450008999678

Vøllestad, J., Nielsen, M.B., \& Nielsen, G.H. (2012). Mindfulness- and acceptance-based interventions for anxiety disorders: A systematic review and meta-analysis. British Journal of Clinical Psychology, 51, 239-260. doi:10.1111/j.2044-8260.2011.02024.x

Vujanovic, A.A., Bonn-Miller, M.O., Bernstein, A., McKee, L.G., \& Zvolensky, M.J. (2010). Incremental validity of mindfulness skills in relation to emotional dysregulation among a young adult community sample. Cognitive Behaviour Therapy, 39, 203-213. doi:10.1080/16506070903441630

Walach, H., Buchheld, N., Buttenmüller, V., Kleinknecht, N., \& Schmidt, S. (2006). Measuring mindfulness - The Freiburg mindfulness inventory (FMI). Personality and Individual Differences, 40, 1543-1555. doi:10.1007/s12671-015-0392-9 